\title{
The Obstacle to the Cultural Integration of Ideological and Political Education and its Realization Path
}

\author{
Sujiao Ji \\ Shandong Foreign Languages Vocational College, Sunshine, 276826, China
}

Keywords: Ideological and political education; Cultural integration; Obstacle; Realization

\begin{abstract}
In the era with rapid development, the importance of ideological and political education culture becomes more and more prominent and it has served as a focus issue explored by the academic world. The ideological and political education has ushered in a brand-new prospect especially during the period of increasingly prosperous socialist culture. Based on this, this text conducts exploration by aiming at the obstacle encountered by the cultural integration of ideological and political education and its realization path.
\end{abstract}

\section{The Cultural Value of Ideological and Political Education}

Cultural value of modern ideological and political education has surface meaning and deep meaning. Culture in the cultural value is in narrow sense as if there includes a thought of idealism. The national characteristics expressed by it remain on the achievements on spiritual level such as the understanding level of things in people's mind, the methods and attitude for understanding the problems, psycho reaction toward the things and passionate sentiment toward beautiful things. In spiritual culture, people's attitude, perspective and value toward things occupy the main position, which endows culture with a kind of national cohesion, national class character and the nature of advancing with times. However, value in cultural value of ideological and political education has meaning on another level which is the so-called deep meaning. It is the link between human and everything in the world just like Marx once said in theory of commodity value that 'commodities are the labor products produced for exchange which are useful to others or the society and the unification of use value and value'. ${ }^{[1]}$ From what we have discussed above, we can have the following judgments. The value owned by an object is determined by its own characteristics. Value is the social attribute of the commodity, reflecting the relationship between man and man. There exists the inter link between culture and value and the two integrate with each other. Culture embodies certain value while value reflects certain culture deposits. The value created by the fruits of labor which are gained from people's own work and can be utilized into their daily life is the cultural value. The cultural value of the modern ideological and political education has profound significance in aspects of cultural transmission and development.

\section{The Obstacle Encountered by the Cultural Integration of Ideological and Political Education}

\section{Cultural Integration of Ideological and Political Education Limited by Balance of Economic Development}

In the factors which limit cultural integration of ideological and political education, economic development level occupies the main position. On the one hand, productivity determines the productive relations, so if the level of productivity increases, then accordingly, the material level of the human will change greatly; On the other hand, developmental level of productivity can lift people's spiritual and cultural living standard, which makes people pursue the high-quality standard of living. With the continuous rise of economy and the stable increase of productivity, people and educators who keep pursuing knowledge will have new understanding toward material life and 
deeper insights toward culture, which promotes further progress of social culture and generates a larger span between material civilization and spiritual civilization.

\section{Idea of Individual Thinking and Social Cultural Prosperity Affected by the conditions at home and abroad}

In the new era of the $20^{\text {th }}$ century, peace and development are the core in our times and along with the effect of this outside environment, there is some long-term transition in international situations and appears many new thinking, new judgment and conflict which more or less change people's old thinking mode. Also people will have come friction and contradiction on certain level of outlook on life and values. Due to the globalization of economy, many concepts about culture and value from abroad will gradually permeate into China and many different ideas, thoughts and life styles abroad will influence people's daily life pattern and value at different degrees. In particular, under the background in which science and technology develop rapidly and soft power of economic culture increases gradually, the idea wins more support among the people ${ }^{[2]}$.

\section{The Powerful Attack of Scientific and Technological Progress on Idea and Prosperous Culture}

In recent years, the scientific and technological revolution promotes the progress of social history greatly but science and technology is a double-edged sword in that it benefits human through promoting economic and social development, makes our lives more colorful and information transfer more rapid and convenient but in the meanwhile, it brings the negative outcome for human existence and development under certain conditions. Spreading information through internet in western countries can be found everywhere. For example, western countries spread their thought of hegemony and publicize the wrong value theory of capitalism to other countries deliberately by taking advantage of various mediums such as internet. Internet is being expanded to every place around the world, which provides convenience for some lawbreakers. They distribute some information which is bad for people's health and issue some information which twists the truth on the internet through utilizing the inauthenticity of the cyber world, resulting in that people lack the credibility toward the real world and are delusional about their attitude and thinking toward life. The development of socialist culture is also bound to usher in a new challenge.

\section{The Negative Factors Generated by Internet Culture}

Internet culture influences what people think as well as how people think. Although the advantages of internet culture far outweigh its disadvantages, it can not be ignored. First of all, values crash into each other. Internet accelerates the information transmission so that the information is spread in time, which gathers cultural concepts from different countries into the big platform of internet in which people express their own opinions and publish their different insights toward the same problem. No one is wrong and no one is right. Everyone can let off the depression in their heart without restraint or release their black sides since the law has no explicit stipulation on that. In this way, we lack the ability of distinguishing between right and wrong and do not have a correct guidance. The most important of all, the teenagers who are in the period of perceiving the world will become more confused about the value and belief of life. Secondly, there appears estrangement in the realistic relationship. The increasing development of internet helps people's hearts gain the excitement and pleasure which can't be obtained from real life so that their spirits get temporary numbness and relaxation. However, the excitement and pleasure stops abruptly once they turn off and leave the computer and annoyance and unhappiness in real life rise in their mind. Certainly, it makes people unwilling to live in real life. Therefore, their internet addiction aggravates. If things continue this way, there must be an absence of necessary communication and exchange among the people. Also the friction and estrangement in daily life are unavoidable. 


\section{The Realization Path for the Cultural Integration of Ideological and Political Education}

\section{Perfecting the Guarantee System of the Ideological and Political Education and Cultural Communication}

To build a set of complete guarantee system of ideological and political education and cultural communication, we can reinforce the following aspects: (1) Preach about the aspects of socialism with Chinese characteristics, ideal and belief and china dream toward people so that people always have a firm belief and correct guidance in their heart no matter what kind of socio-culture they encounter and can avoid getting distracted by anything bad.(2) Guide people to form a good habit in which they judge the good and evil of cultural information voluntarily and scientifically, select the favorable information which helps lift their personal quality and improve their own scientific and cultural quality comprehensively by themselves. (3) Based on the basic condition of our country at this stage and the increasing demand of people, set up scientific life attitude, value and moral model during the period of political socialization and in particular, emphasize the education toward the behavior of the teenagers and regulate their conduct strictly.(4) Organize various social activities actively so as to let the public involve in them personally and experience the grand blueprint of socialist construction personally. Then the social experience, economic construction and scientific and technological progress become integrated, which plays the important role. Therefore, people's scientific literacy and work ability gain drastic improvements during the process of their own practice, which attains the result with half effort.

\section{Consolidating the Idea of Cultural Integration of Ideological and Political Education}

To consolidate the idea of cultural integration of ideological and political education better, we must deal with the interrelationship between ideological and political education and culture better. Strengthen the perfect combination of ideological education and culture instead of conducting combination or distribution simply and mechanically or utilizing other methods. We should make the two bond together with organic force and degree, well-distributed and coordinated in proportion and only in this way can their role be developed to the fullest and can their own ideological morality and scientific and cultural quality reach the qualitative leap. To consolidate the idea of cultural integration of ideological and political education, it requires not only that people need to enrich themselves by learning independent study and relying on the successful experience from the civilization history of human development, but also that we keep understanding the profound Chinese culture and the things worth learning in western culture[4]. Take the development road with Chinese characteristics and enrich the connotation and theoretical significance of ideological and political education with advanced ideas. Only the ideological and political education and cultural integration with mutual integration, imitation and advancement between Chinese and western culture can have the wonder of using different approaches to achieve equally satisfactory results and develop the huge advantage together.

\section{The Measurement for the Improvement of Cultural Integration}

In the cultural integration of ideological and political education, there are three expression approaches which are the direct fusion method, the euphemistic and implicit fusion method and the compound method of the two fusions.(1) Direct fusion method. It is the so-called being straight to the point, which integrates the related thoughts of culture into the ideological and political education directly. Then these thoughts are displayed through people's understanding level of these contents so as to reach the fusion of ideological and political education and culture. It just likes that during the period of cultural construction and the implementation of ideological and political work in the enterprise, conduct the educational practical activities of enterprise culture, the struggle of the enterprise and the behavior objective of the enterprise toward the employees according to related political norms and the development prospect of the enterprise so that the employees can truly feel the responsibility and duty as part of the enterprise. It is the essential wealth for the enterprise cultural 
construction as well as the necessary components of the ideological and political work of the enterprise. (2) Euphemistic and implicit fusion method. It's the indirect fusion method which displays the ideological and political contents through the recreational activities in various forms, so that the educators can feel the charming of the culture in relaxed and comfortable atmosphere and have a more tacit understanding. In many aspects, we can express our emotion through the objects by adopting the method which combines emotion with scenery and in this way, people can have more fighting will to face the trivial matters in life. (3) The compound method of the two fusions. It is the method that combines the direct one and the indirect one and plays the role together. The simplicity of direct fusion and the significance of indirect fusion integrate with each other, learn from each other's strong points to offset the weaknesses and achieve mastery together. The effect exerted from the combination of the two is immeasurable.

\section{Developing the Modern Culture of Ideological and Political Education and Improving the Environment of Modern Ideological and Political Education}

The development and improvement of the modern cultural environment of ideological and political education should start from the following aspects: First of all, establish the cultural soul of progress. Cultural soul is the inheritance and gathering of all the ideologies and values in human society. Advanced cultural soul can have the effect of scientific guidance and promotion on socialized big-production, coordinate the contradictions among various factors in social production and guide the rapid development of social production scientifically. Modern construction of ideological and political education does advocate the advanced spiritual culture and it takes root and sprouts among the public through various social activities. It forms a flood current to guide the current field of spiritual culture. Secondly, develop and expand the traditional material culture positively. Today, with the increasing reinforcement of the world cultural communication and integration, facing the strong attack from western culture and under the background of co-existence of multi-cultures, strengthen the national cohesion and the social centrifugal force and establish the core value of socialism through the study and vigorous promotion of the fine traditional culture in our country[5]. Secondly, conduct the structural reform toward the system. System is the regulation or standard behavior which requires the abidance of all people. Strengthening the deep combination of system cultural construction and system innovative idea and forming a favorable cultural atmosphere for the system are the main environmental assistance forces for reinforcing the integration of modern culture of ideological and political education into construction. Influence the thoughts and behavior of people at various social classes from system coercion to subtle influence and make people respect and abide by the mainstream social cultural value and related specifications required by the regulations. In the end, build the basic specification in various aspects of the society with the goal of providing a mode to guide people's behavior and pass on positive energy to the society continuously and deepening people's sense of belonging toward the society and the consciousness of ownership. For example, the professional model in various professions of the society can publicize the traditional morality and protocol[6].

\section{Promoting the Spiritual Cultural Industry and its Products Production Vigorously}

Under the background of continuous development of economic technology, educational enterprise of scientific-technological culture and various media industries gain great development and prosperity, playing a crucial role in satisfying people's increasing demand for spiritual culture and accelerating the people's construction of ideological politics and cultural morality. Moreover, the development of ideological and political education enterprise must take the big development of social cultural industry as the premise. Therefore, intensifying the construction of spiritual cultural enterprise and making a good job of the development and market operation systems of various culture media products play a crucial role in promoting the social economy, cultural construction and modern construction of ideological and political education. 


\section{Conclusion}

In conclusion, under the general background of social culture and social development, speeding up the integration construction of ideological and political education and social culture not only benefits the reform and innovation of ideological and political education and strengthens the practicability and guidance function of ideological politic work, but also establishes a solid spiritual guarantee for the socialist economic development, meets the requirement of people's spiritual culture, arouses people's passion for the social economy and culture construction and provides a powerful momentum for the economic and social development. In real life and work, we should keep finding out the obstructive factors which influences the cultural integration of ideological and political education and adopt effective measures actively to promote the smooth realization of cultural integration.

\section{References}

[1] Liu Enming.The Cultural Inheritance and Innovation Study of Ideological and Political Education.Guangzhou: Guangdong People's publishing House,2009:231.

[2] Gu Youren. The Innovation of Chinese Traditional Culture and Ideological and Political Education.Hefei: Anhui University Press, 2011:167-168.

[3] Zhou Wenzhao. A study about the Necessity and Entry Point for the Integration of Ideological and Political Work into Enterprise Cultural Construction. Enterpriser Information, 2010,(12)

[4] Li Yuhong, Menghong. The Ideological and Political Education Functionalism of the Honest Cultural Construction. Studies in Ideological Education,2009,(12):87-88.

[5] Huang Yinshan. The New Development of the Realization Path for the Modern Ideological and Political Education. Journal of Inner Mongolia Normal University(Education and Science Edition), 2014,(04):34-35.

[6] Shi Shucheng. Modernization: The new Project for the Innovative Development of Ideological and Political Education. Theoretical Front in Higher Education,2011,(04):42-45. 